\title{
Quality of life domains relevant to people living with HIV and AIDS who are on antiretroviral therapy in Swaziland
}

\author{
Authors: \\ Theresa T. Ntshakala ${ }^{1}$ \\ Thandisizwe R. Mavundla ${ }^{1}$ \\ Bethabile L. Dolamo ${ }^{1}$ \\ Affiliations: \\ ${ }^{1}$ Department of Health \\ Studies, University of \\ South Africa \\ Correspondence to: \\ Thandisizwe Mavundla \\ Email: \\ mavuntr@unisa.ac.za \\ Postal address: \\ PO Box 392, UNISA, \\ 0003, South Africa \\ Dates: \\ Received 14 Jan. 2012 \\ Accepted: 14 Oct. 2012 \\ Published: 06 Dec. 2012 \\ How to cite this article: \\ Ntshakala, T.T., Mavundla, \\ T.R. \& Dolamo, B.L., 2012, \\ 'Quality of life domains \\ relevant to people living \\ with HIV and AIDS who are \\ on antiretroviral therapy \\ in Swaziland', Curationis \\ 35(1), Art. \#87, 8 pages. \\ http://dx.doi.org/10.4102/ \\ curationis.v35i1.87
}

(C) 2012. The Authors. Licensee: AOSIS OpenJournals. This work is licensed under the Creative Commons Attribution License.
Quality of life (QOL) domains that are context specific to people living with HIV and AIDS (PLWHA) who are on antiretroviral therapy (ART) in Swaziland are unknown. This presents a problem when research has to be conducted on QOL of PLWHA who are on ART. As a result, this study was conducted to identify, validate and describe domains necessary to assess QOL of PLWHA, who are on ART in Swaziland. A qualitative, explorative, descriptive, and contextual design was used for this study. The first phase dealt with a review of fifty existing QOL definitions and the identification of the common domains amongst them. Findings from this review revealed that the most common domains of QOL are the physiological, psychological, spiritual and socio-economic domains. The second phase was the validation of the above common domains identified from the examined QOL definitions to make them context specific to PLWHA who are on ART in Swaziland. A workshop was used to validate the domains with expert nurses involved in the care of PLWHA in Swaziland. The experts in ART care were trained on ART and had more than a year's experience of working with PLWHA who are on ART. The validation process revealed that the essential context specific domains to consider when assessing QOL of PLWHA who are on ART are, (1) physiological domain, (2) psychological domain, (3) spiritual domain, (4) socio-economic domain, (5) cognitive domain, and (6) environmental domain. The process of validation of the domains was important as two extra domains were revealed, which were not initially recognised by the researcher during literature review.

\section{Introduction}

The prevalence of HIV infection in Swaziland increased from 3.9\% in 1992 to $26.1 \%$ in 2007 amongst people aged 15-49 years and there was a high estimated HIV incidence rate of 3\% (Ministry of Health National Multi-sectoral Strategic Framework for HIV and AIDS 2009-2014:23). As a means of prolonging the lives of PLWHA, the government of the Kingdom of Swaziland introduced ART in 2001. Both the public sector and non-governmental organisations offer ART. By September 2008, 30337 people (48\%) were receiving ART in Swaziland (Ministry of Health National Multi-sectoral Strategic Framework for HIV and AIDS 2009-2014:23).

Although ART may seem to be a saviour to many PLWHA, the QOL of these people remains a concern. According to Carr, Gibson and Robinson (2001:1240), health care is changing and the two driving factors for this change are the recognition of the importance of the social consequences of disease and the acknowledgement that medical interventions aim to increase the length and quality of survival. In order to increase the length and the quality of survival of PLWHA who are on ART, it is essential to evaluate their QOL using relevant QOL domains, as in most instances in illness, QOL becomes more important than quantity of life. Evaluation of the QOL of PLWHA may help capture the nature of the individual's feelings and perceptions that prevail as a result of the effects of HIV, AIDS and ART.

Furthermore, regarding health care intervention, Addington-Hall and Kalra (2001:1417), state that: 'One of the reasons behind the rapid development of quality of life measures in health care has been the growing recognition of the importance of understanding the impact of health care interventions on patients' lives rather than their bodies'. It seems, therefore, important to realise that ART is for the holistic improvement of PLWHA and not only the physical aspect. Holistic improvement necessitates consideration of the fundamental domains of QOL.

The World Health Organisation (WHO) (1995) defines QOL as 'the individual's perception of his or her position in life, within the cultural context and value system, his or her goals, expectations, parameters, and social relations, and is a broad-ranging concept affected in a complex way by the person's physical health, psychological state, level of independence, social relationships, and 
their relationship to salient features of their environment (WHOQOL group 1991, in Berlim \& Fleck 2003:3). This definition implies that QOL is multidimensional and culture bound. What is considered a good life varies between different individuals and different societies and cultures, and it may be misleading to take a conception of QOL that has been developed in one cultural context and apply it to other cultures, or even to different ethnic communities living within the same geographical area (Keith 2001:52). Furthermore, Keith (2001:52) argues that the core attributes of QOL may vary from one culture to another, in which case the search for a general, cross-cultural definition of QOL may be misguided. The researcher has noted that QOL has, in many instances, been measured by researchers using preexisting instruments. Using pre-existing instruments has some methodological limitations, as they were developed in contexts different from the Swazi context. It is important, therefore, that QOL domains that are relevant to PLWHA in Swaziland who are on ART are known and that their QOL assessment is done using the relevant context-specific domains of QOL, so as to offer holistic and cultural congruent care.

\section{Research question}

In line with the above-mentioned argument, this study was aimed at answering the following question: What are the essential domains that need to be considered when assessing QOL of PLWHA in Swaziland who are on ART?

\section{Research purpose}

The purpose of this research was to examine the concept of QOL, identify the major domains of QOL and validate these domains to make them context specific to PLWHA who are on ART in Swaziland.

\section{Contribution to field}

The importance of this study lies in the recognition that ART was introduced for improvement of QOL of PLWHA in Swaziland. QOL is a multidimensional phenomenon that is culture bound. In order for a valid QOL assessment, relevant context specific domains of QOL have to be utilised. Using context specific domains means offering cultural congruent care which is client centred and holistic. A client centred approach to ART care will result in the empowerment and improvement in QOL, whilst preserving the dignity of PLWHA who are on ART in Swaziland.

\section{Research method and design Design}

The researcher utilised a qualitative, exploratory, descriptive and contextual design for this study.

\section{Data collection}

The process of data collection began with extensive literature review of the concept of QOL. Fifty definitions of QOL were analysed. Through this analysis, common domains of QOL were identified. The next phase was the validation process of the domains to contextualise them to PLWHA who are on ART in Swaziland. The process of validation of the domains was done using a workshop with expert nurses involved in the care of PLWHA in Swaziland. This method of data collection was efficient because the researcher was able to bring the ART experts into one venue at the same time, thus she was able to obtain viewpoints of these experts at the same time, enabling the validation process of the domains.

\section{Population and sampling}

Participants were recruited from one urban referral hospital and one urban clinic in the Manzini region. These institutions, the Raleigh Fitkin Memorial Hospital (RFMH) and the King Sobhuza II (KSII) Clinic, were deliberately selected because they render ART services. Permission was obtained from the managers of these institutions after stating fully the nature of the research. The managers, in liaison with the researcher, used a purposive sampling technique to recruit candidates who were considered to be experts in ART care to attend the workshop. Inclusion criteria were those ART nurses who had undergone training in ART care and had more than a year's experience of working with PLWHA who are on ART and, as such, they were considered experts in the field. Participation was voluntary. In total, 18 expert nurses agreed to attend and participate in the workshop. After obtaining verbal consent from the participants, the researcher spent about 20 minutes with each participant, familiarising them with the workshop and explaining the overall purpose of the research.

Of the 18 nurses that agreed to participate, 16 nurses made themselves available for the workshop. This sample size was adequate to elicit sufficient information to validate the domains of QOL, which were identified by the researcher through a literature review. All the participants had a similar background, having more than a year's experience of caring for PLWHA who are on ART.

First, there was discussion of the concept of QOL. This was followed by a brief discussion of the quality of care of PLWHA who are on ART in Swaziland. The purpose of these discussions was to stimulate the thought content of participants, so as to enable them to share their experiences of working with PLWHA on ART.

Since the participants were a homogeneous group, it was easy to divide them into two groups of eight participants. Each group was small enough for each member to participate. The two groups chose a leader, a secretary and a presenter. The leader was responsible for coordinating group activities and focusing the group. The secretary was responsible for documenting the group's inputs, and the presenter presented their conclusions on behalf of the group. They were required to reflect on their experiences of caring for PLWHA and to discuss the QOL of PLWHA in Swaziland who are on ART. Discussions focussed on QOL, care given to PLWHA and their QOL.

After one and a half hours of deliberations, each group was requested to present their inputs. Presentations were made with the aid of flip charts, notes and the whiteboard. These 
were video-recorded for purposes of authenticity and data analysis. The researcher documented all the participants' inputs. After each presentation, the researcher made a summary of major themes identified. This was done to ensure that important issues were not missed and were captured correctly. Presentations from both groups lasted one and a half hours.

\section{Debriefing}

Debriefing means communicating with study participants after participation is complete regarding various aspects of the study (Polit \& Beck 2008:182). Debriefing ensures the credibility of the research findings. Credibility is considered by Lincoln and Guba as an 'overriding goal of qualitative research' (Polit \& Beck 2008:539).

At the end of the presentations, there was a debriefing session with the study participants. Debriefing was done to ensure that important information concerning ART was captured. This helped to develop a clear picture of the participants' inputs. Participants were given the opportunity to ask questions and give more input on the information captured by the researcher.

\section{Data analysis}

Data analysis is the process of bringing order, structure and meaning to the mass of collected data (De Vos, Strydom, Fouche \& Delport 2005:333). Data were analysed using Tesch's framework of data analysis as described in Creswell (2002:256-283). This required the researcher to carefully read her notes, the participant's notes and view the video. Since the group discussions yielded a lot of rich data, the researcher used a coding system to transform the raw data into a standardised form for data processing and analysis (Polit \& Beck 2008:749). Coding is a means of categorising, and a code is a symbol or abbreviation used to classify words or phrases in the data (Burns \& Grove 2005:548). The researcher attached codes to corresponding data that defines different domains of QOL. After data analysis was complete, the researcher returned to the participants to confirm the validated domains.

\section{Ethical consideration}

Because ethical issues in social research are important, most of the professional associations have created and published formal codes of conduct describing what is acceptable and unacceptable professional behaviour (Babbie \& Mouton 2003:528). For this reason, the ethical and moral principles laid down by the Democratic Nursing Organisation of South Africa (DENOSA 1998), the Swaziland Scientific and Ethical Guidelines, and the ethical standards contained in Burns and Grove (2005:176-208) and Polit and Beck (2008:167-192) were adhered to in this study. The following principles were applied by the researcher during the conduct of this study, namely: informed consent, autonomy, confidentiality and anonymity, and privacy.

\section{Trustworthiness of the study}

Trustworthiness was ensured by applying Lincoln and Guba's model of assessing trustworthiness. The four criteria for assessing trustworthiness used by the researcher are, (1) credibility, (2) transferability, (3) dependability, (4) and confirmability (Polit \& Beck 2008:539). Credibility was achieved through prolonged engagement with the participants, triangulation, member checking, peer examination and referential adequacy. Transferability was ensured by the use of purposive sampling of participants and thick description of methods and participants responses. The use of thick description of methods and participants responses also ensured dependability because there can be no credibility without dependability (Babbie \& Mouton 2003:278). The use of notes, tape records, and the final report ensured confirmability of this research.

\section{Results}

Through literature review, the researcher identified that the most common domains of QOL are the physiological, psychological, spiritual and socio-economic domains.

In as much as the above four domains of QOL obtained through the examination of existing QOL definitions were not directly revealed to the participants, it is worth noting that through the participants' discussions and the data analysis, these domains were revealed by participants as they are important in assessment of the QOL of PLWHA who are on ART in Swaziland. In addition, participants identified two other domains that they also considered important. The two domains are the cognitive and environmental domains. Even with the domains obtained from literature review, participants had some important information to add. The coded domains of QOL that were identified by the participants as important in the care and improvement of QOL of PLWHA who are on ART in Swaziland (Box 1).

\section{Discussion}

The following section discusses the research findings according to the domains identified by the participants as important for PLWHA in Swaziland who are on ART.

\section{Physiological domain}

The domain of physical well-being pertains to individuals' perception of their own bodily functions, including disease symptomatology, side effects of medication or general physical well-being (Henderson et al. 2008:369). The participants identified the importance of the physiological

BOX 1: Coded quality of life domains identified

$P h$ for the physiological domain
$P s$ for the psychological domain
$S p$ for the spiritual domain
$S e$ for the socio-economic domain
Co for the cognitive domain
En for the environmental domain


domain in the improvement of QOL of PLWHA in Swaziland who are on ART. Specifically on this domain, participants emphasised the importance of nutrition and intimacy. They felt that most PLWHA in Swaziland are poor and unable to meet their need for adequate nutrition, which is vital for treatment adherence, immunological development and treatment success. They stated that the rampant poverty in Swaziland made it impossible for clients to adhere to ART. One participant stated that:

'In Swaziland, I feel we [nurses] are going nowhere in the fight against the epidemic, because of poverty. Poverty has promoted prostitution, and prostitution has increased the prevalence of HIV and other sexually transmitted infections, and, as such, provision of ARVs will do little to improve the lives of the people. We should see how we deal with the problem of hunger first, before giving ARVs.' (Participant 7 from group 2, Female, Senior nurse, Aged 41yrs)

There was, however, a feeling amongst participants that nurses cannot just deny the drugs to those who need them, because of hunger. As a means of dealing with the problem of hunger, one concerned participant stated that:

'It is a pity, because we educate people about a balanced diet, yet some families cannot afford even a plate of porridge. How do we expect them to afford the luxury of a balanced meal three times a day? Maybe government can do something, like offering some incentives in the form of food or money, to alleviate the problem of hunger.' (Participant 3 from group 2, Female, Senior nurse, Aged 39 yrs)

There was disagreement amongst the participants concerning the notion of government giving food and financial assistance to PLWHA. Some participants felt that giving assistance would be like rewarding them for having HIV, an act that could have a negative impact on the epidemic. One participant mentioned that:

'In some countries where there is financial assistance for PLWHA with a low CD4 cell count, of 200 and less, PLWHA deliberately stop taking ARVs, to drop the CD4 cell count, so that they can get the assistance. The mere fact that government is providing assistance means that she is rewarding them [PLWHA] for being HIV-positive, and people will deliberately infect themselves. If government provides financial aid, she has to provide them for all other chronic illnesses.' (Participant 1 from group 1, Female, Senior nurse, Aged 43yrs)

Participants finally reached a consensus that, as a strategy for dealing with poverty and poor adherence, government should provide food and financial assistance for PLWHA in Swaziland who are on ART.

Much research has been conducted on the role of nutrition in HIV infection, and it has been concluded that nutrition is critical for PLWHA, since it prevents muscle wasting, strengthens the immune system, reduces viral mutations, decreases the incidence and severity of opportunistic infections and lessens the debilitating symptoms of HIV (McMeans 2001:97). The problem of poverty and malnutrition was also identified during the Abuja Summit of 2001. Abuja Declaration No. 4 states that: 'We recognise the role played by poverty, poor nutritional conditions and underdevelopment in increasing vulnerability'. In response to the above declaration, Swaziland adopted the eight Millennium Development Goals (MDGs). Although Millennium Goal No.1 is aimed at eradicating poverty and hunger, these problems still prevail in Swaziland.

Concerning intimacy, participants felt that it was as important to PLWHA as to anyone else. Participants felt that PLWHA in Swaziland are deprived of love, intimacy and sexual satisfaction due to the stigma associated with the infection and ARVs, yet love is important for survival. One participant mentioned that:

'Even the nurses themselves think that once one is HIV positive, he or she should not engage in sex and have children, yet we have heard some PLWHA claim that ARVs have increased their sexual desire. We need to do a baseline assessment to examine the effects of ARVs on sexual desire and change our [nurses] attitudes that HIV means no sex and no children.' (Participant 6 from group 2, Female, Junior nurse, Aged 32yrs)

According to Kasiram, Dano and Partab (2006:55), intimacy and sexuality are integral to the human experience irrespective of HIV status. However, intimacy is elusive when accompanied by hopelessness and negativity. In addition, the above authors have noted that both HIV and intimacy are topics that are shrouded in secrecy and silence, and that health professionals should provide an environment that helps nurses move beyond seeing only illness and stigma to being able to render compassionate care.

\section{Psychological domain}

Neuman in George (2002:343) defines the psychological variable of a person as: 'The mental processes and relationships'. The psychological aspect of PLWHA was mentioned by participants as important in PLWHA, as it is linked to their QOL. They emphasised that any health care intervention should consider the psychological aspect of PLWHA. One major psychological problem that was noted by participants is AIDS-related stigma and discrimination. Participants felt that PLWHA in Swaziland who are on ART still suffer self-stigmatisation, and are stigmatised by their families, and by communities and health workers. One participant commented that:

'One problem that is common in all PLWHA is stigma. It is a pity, because we [nurses] are the perpetrators of stigmatisation. We stigmatise them [PLWHA] by the bad labels that we give to HIV for example, umbulalave (nation killer), mashayabhuce (destroyer), silwane (animal), ligciwane (a germ), and ingculaza (AIDS). We may talk of measures to combat stigma, but it is still within us. We still stigmatise them one way or the other.' (Participant 7 from group 2, Female, Senior nurse, Aged 41yrs)

Concerning the labels given to PLWHA, one participant mentioned that:

'The intention of these unpleasant labels was not to stigmatise them [PLWHA] per se, but to label the epidemic so badly that people would do all in their power to take preventive measures.' (Participant 1, From group 2, Female, Senior nurse, Aged 37yrs)

Concerning the relationship between stigma and ARVs, participants felt that ARVs have not lessened the stigma, but 
have increased it in that the ARVs are difficult to hide and they serve as a marker for HIV infection. One participant stated that:

'We hoped that with ARVs, PLWHA will live longer and stigma will be reduced, but what is noted is that, seemingly, ARVs have increased stigma as it is seen in the clinics whereby PLWHA hide their tablets by putting them in different containers.' (Participant 1 from group 1, Female, Senior nurse, Aged 43yrs)

Consequences of stigma caused by ARVs identified by participants include depression, loss of dignity, uncertainty, hopelessness, non adherence to ART, drug resistance and a poor QOL.

Research studies suggest that stigma and discrimination are a problem that is still faced by PLWHA, and which is undermining health workers' efforts to improve PLWHA's QOL. A lot of research has been done on stigma, and it has been concluded that stigma is linked to the QOL of PLWHA (Emlet 2007:740; Holzemer et al. 2009:161).

There is substantial evidence in support of participants' idea that stigma exacerbates the problems faced by PLWHA. Hughes, Davis and Gudmundsdottir (2008:342) state that despite overwhelming evidence of the success of antiretroviral therapies in reducing HIV-associated morbidity and mortality, stigma and discrimination persist, undoubtedly in part because of cultural taboos concerning sex and drug use, and their links to viral transmission. In addition, a study conducted by Uys et al. (2009:1059) supports the participants' findings by concluding that stigma is greater for people that are on antiretroviral drugs than for those that are not on ARVs.

One important measure to combat stigma that was identified by participants was the maintenance of confidentiality. One participant was of the view that:

'Although we [nurses] are now and again reminded of the importance of maintaining confidentiality regarding all client information, it appears that we are losing sight of its importance, and this unfortunately results in stigmatisation of PLWHA. Sometimes we want to normalise how people view HIV and AIDS and ARVs, yet PLWHA will feel stigmatised.' (Participant 5 from group 2, Female, Senior nurse, Aged 38yrs)

There was, however, disagreement amongst the participants concerning the issue of confidentiality. Whilst some felt that confidentiality had to be maintained, others felt that maintaining confidentiality would cause the infection to spread. Participants finally agreed that nurses have both the responsibility of maintaining confidentiality and a unique opportunity to overcome stigma within their professions and workplaces. Their professional codes of ethics and conduct, social and professional authority and their ability to act as educators and role models for their communities all place them under the obligation to be change agents for reducing stigma. The Code of Professional Nursing Conduct (1978) for Swaziland states that nurses are to maintain confidentiality, except where disclosure is required by law or order of a court, or is necessary in the public interest. Furthermore, participants stated that the active involvement of PLWHA is central in the fight against stigma, and the mass media can serve as powerful tools to help reduce stigma. In addition to reducing stigma, preservation of the dignity of PLWHA was identified as important in their care.

\section{Spiritual domain}

The researcher noted that spirituality was used synonymously with religion by all participants, but it was made explicit by the researcher that religion refers to an organised system of beliefs concerning the cause, nature and purpose of the universe, especially beliefs in or the worship of God or gods, whereas spirituality refers to something that is born out of each person's unique life experiences and his or her personal effort to find purpose and meaning in life (Andrews \& Boyle 2003:436).

Participants felt that spirituality is an important dimension of life that needs to be considered in the care of PLWHA. The participants stated that the spiritual dimension of an HIVinfected individual encompasses the need to find satisfactory answers to the questions concerning the meaning of life, the illness, and death. They felt that an individual with HIV may seek to find meaning and purpose in life after having been diagnosed as having HIV and put on ART. One participant mentioned that:

'When one is diagnosed with a chronic illness like HIV and AIDS, he or she needs something to rely on. Something that will not judge the patient as to how he got infected. Something that promises a brighter future.' (Participant 3 from group 2, Female, Senior nurse, Aged 39yrs)

The findings of the nurses' workshop concerning the relationship between spirituality and health are consistent with other studies linking spirituality and health. Spirituality may have a positive impact on physical health and healthrelated QOL (Dalmida 2007). Religiosity and faith significantly influence adherence (Holstad et al. 2006). Spiritual practices act as a buffer when individuals are faced with negative life events (Scarinci et al. 2009:69). The use of spiritual coping or spiritual practices may enhance self-empowerment, leading individuals to find meaning and purpose in their lives (Baldacchino \& Draper 2001:838). A strong sense of coherence and strong spirituality are associated with higher ratings of QOL (Delgado 2007:233).

Participants stated that the spiritual aspect of PLWHA is often ignored in ART clinics. One participant who was concerned that the spiritual dimension of clients was often ignored stated that:

'We do have church services in the mornings, but maybe it is just a general church service, and what we need are spiritual support groups for spiritual guidance, that will specifically be focused on HIV and AIDS, to bring back hope and trust.' (Participant 1, From group 2, Female, Senior Nurse, Age 37 yrs)

The study participants also felt that nurses should conduct spiritual assessments so that the patient can be given the necessary spiritual nursing care. Participants mentioned that spiritual assessments can provide nurses with information about how patients view life, death, and health concerns. 


\section{Socio-economic domain}

The socio-economic domain deals with social support, community roles, community integration, participation and employment. The participants recognised the importance of considering the socio-economic dimension of an individual's life when assessing his or her QOL. Participants stated that socio-economic status is related to health as lack of money affects the quantity and quality of resources that the client can have and negatively influences QOL. One participant stated that:

'Poverty in Swaziland is a common problem. If Swaziland can deal with poverty, most of the problems that spread the virus and cause defaulters can be eliminated. We know that poverty leads to poor nutrition, poor living conditions and poor access to health care, which are all reasons for the high prevalence of HIV in Swaziland and a poor QOL for those on ART.' (Participant 4 from group 1, Male, Junior nurse, Aged 30yrs).

The above is consistent with the views of Stanhope and Lancaster (2004:123), who state that socio-economic status is inversely correlated with mortality and morbidity for almost every disease. Poverty in Swaziland is confirmed by the Ministry of Health and Social Welfare National Multisectoral Strategic framework for HIV and AIDS (2006-2008), which states that the majority of people in the country (69\%) are classified as poor (i.e. living below the poverty line of $€ 128.60$ (US\$22) per month), possibly due to poor distribution of available resources and rising unemployment, which is estimated to be at $29 \%$. Although Swaziland has enacted Millennium Development Goal No.1, which is aimed at eradicating poverty and hunger, and health sector funding has improved from $7.9 \%$ of the national budget in 2007-2008, to $10.6 \%$ in $2008-2009$, and $17 \%$ in $2009-2010$ (which is above the $15 \%$ minimum stipulated by the Abuja Declaration); the problems of poverty and hunger still exist.

\section{Cognitive domain}

Cognitive abilities shape the way a person thinks, including the ability to understand factors involved in illness and to apply knowledge of health and illness to personal health practices (Potter \& Perry 2005:164). Participants revealed that the cognitive domain is important in assessment of the QOL of PLWHA who are on ART. They mentioned that knowledge has a direct influence on health and QOL. Lack of knowledge has a negative impact on the epidemic and QOL.

Both participant groups identified a knowledge deficit about ART and HIV amongst PLWHA and the nurses. They identified that lack of knowledge of HIV and AIDS and ART is the major cause of non-adherence to ART. The nurses stated that despite having worked with PLWHA for more than a year, they still lacked knowledge on ART and lacked confidence at times.

'We are expected to educate people about HIV and AIDS and ART, yet even we as nurses are not currently updated. We lack knowledge and competence.' (Participant 6 from group 2, Female, Senior nurse, Aged 32yrs).
In agreement with the participants' inputs about the importance of the cognitive domain, Abuja (2001) Declaration No. 10 states that:

'We recognise the essential place education, in its widest sense, has played, and will continue to play, in the fight against HIV and AIDS in Africa. Education constitutes the most powerful, cost-effective tool for reaching the largest number of people with information and personal development strategies that promote long-term behaviour change. We commit ourselves to scaling up the role of education and information in the fight against HIV and AIDS.'

The Ministry of Health and Social Welfare Strategic Plan (2006-2008), identified inadequate public awareness of HIV and AIDS and the epidemic in Swaziland. The Plan states that although several studies indicate that a high proportion of the population is aware of the AIDS epidemic and understands its dangers, misconceptions about the disease are still very common. This may be due to the fact that there are claims by some faith healers and traditional healers that they can cure $\mathrm{HIV}$, the promotion of unproven drugs and treatments, and practices such as sexual intercourse with virgins.

The study also revealed that the cognitive domain of PLWHA is important in their assessment since it deals with the thought content of PLWHA. HIV and AIDS are related to behaviour, which in turn is influenced by the thought content of the individual. According to participants, PLWHA may be preoccupied with thoughts related to a world of nothingness, stigma and discrimination, a predetermined life, the incurability of the infection and lifelong ART. Participants stated that nurses have not addressed the thinking aspect of patients. One participant commented that:

'What is currently happening is that nurses only concentrate on the physical aspect of the person. As long as he or she is gaining weight and has no opportunistic infections, it is assumed that all is well. We have totally forgotten to nurse the person holistically.' (Participant 8 from group 1, Female, Senior nurse, Aged 33yrs).

\section{Environmental domain}

According to Gillespie and Kadiyalla (2005:11), HIV and AIDS is environmentally driven. Louis Pasteur in Gillespie and Kadiyalla (2005:11), identified the importance of the environment in every illness and declared that 'the microbe is nothing, the terrain is everything.'

The participants acknowledged that the environment was very important in caring for PLWHA on ART. They emphasised that if the patient's environment is not conducive, nurses' efforts to improve the QOL of PLWHA on ART will be useless. Participants' inputs about the importance of the environmental domain are confirmed by Kirk (2002:60), who states that: 'The environment has long been accepted as a legitimate domain of nursing, and its significance is acknowledged through nursing models such as those of Roy and Rogers.'

According to participants, the environment of PLWHA deals with the socio-cultural system, the health care system and 
the political system. The health care system of Swaziland consists of the formal and the informal health care sectors. The formal health care sector is based on Western medicine and consists of public and private health services, including Rural Health Motivators (RHMs). The informal health care sector consists of traditional health practitioners, community and family caregivers, PLWHA, and other unregulated service providers. Participants noted that there are many problems inherent in the health system in Swaziland. These include acceptance of traditional health practitioners and other unregulated service providers, as well as poor health sector funding.

Participants stated that in Swaziland, the traditional health system and other unregulated health services have a wider acceptance amongst PLWHA for obvious reasons of availability and the belief in their efficacy. One participant said:

'We are Swazis and our culture does not believe in organisms that are not visible to the naked eye. Whenever something bad happens, it is caused by someone and as such AIDS is never accepted by everybody as a natural occurrence. It is attributed to witchcraft.' (Participant 1 from group 2, Female, Senior nurse, Aged 37yrs).

Research by Nyika (2007) of the Centre for the AIDS Programme of Research in South Africa, warns that there are loopholes in the practice of African traditional medicine that have the potential to expose participants to harm, due to the fact that these traditional medicines have not been subjected to the same rigorous assessment of their effectiveness and safety as licensed medicine has. Hence, the issue of African traditional medicine is treated with laxity, especially where ethical and regulatory issues are concerned.

Although appreciative of the fact that ART services are offered free, participants stated that these services were still centralised, inefficient and unresponsive to new needs, contrary to the Ministry of Health and Social Welfare National Health Policy (2007:2) mission statement, which states that services should be available, affordable, accessible and socially acceptable. The participants stated that the services are not available in outreach clinics, but are only available in private clinics and referral hospitals, which are very far from most of the clients, and that PLWHA cannot afford the travelling expenses. This situation negatively influences QOL of PLWHA.

The political system deals with power. Power includes not only material or physical resources, but also psychological and cultural aspects. Participants felt that PLWHA are powerless most of the time when it comes to decision making. Their rights are often violated, as some employers have set the prerequisite of HIV status disclosure for employment. Some influential leaders feel that PLWHA should be branded on their buttocks, so that they are identified and they do not infect others, yet protection of human rights and democratic governance are vital in all efforts to provide care and to prevent and mitigate the effects of the epidemic.
The Ministry of Health and Social Welfare National Health Policy (2007:11) states that fundamental human rights will be respected in the course of provision of all health services. Whiteside in Dickson (2006:3) asserts that democracy and good governance may help slow the epidemic and minimise its impact. He argues that: 'A fair legal system, respect for human rights, a credible and competitive electoral process that makes HIV and AIDS an election issue, a vibrant and active civil society and increased transparency, may have an impact on combating the spread of the epidemic. Participants also noted that not all institutions use the same ART guidelines when rendering care to PLWHA, and that this has sometimes resulted in problems with client referrals.'

\section{Limitations of the study}

The findings drawn from this study provided an insight into understanding QOL domains that are relevant to PLWHA in Swaziland who are on ART; however, the findings should be understood in light of some limitations. The study was qualitative and exploratory and was conducted on a limited sample of registered nurses. This means that the findings cannot be generalised to any other culture beyond the Swazi culture. The domains can only be contextualised amongst PLWHA in Swaziland. Due to financial and time constraints, nurses from only two urban ART health care institutions were invited to attend the workshop. This means that the domains were validated by ART experts from urban settings only.

\section{Implications for nursing practice and further research}

Despite the mentioned limitations of the study, the findings have important clinical considerations:

- The study was aimed at validating the domains of QOL for PLWHA in Swaziland who are on ART. These domains must be used in the assessment of QOL of PLWHA, to offer holistic quality care, resulting to improvement to their QOL.

- Cultural and spiritual care should be regarded as vital in the care of PLWHA. Nurses should render culturally and spiritually competent interventions.

- Continual in-service education should be provided to nurses on HIV and AIDS, ART and adherence management.

- Since the domains were validated by nurses from an urban setting only, validation of such domains is warranted for rural settings.

\section{Conclusion}

The purpose of this two phase research was to examine the concept of QOL, identify the major domains of QOL and validate these domains to make them context specific to PLWHA who are on ART in Swaziland.

In phase 1, the researcher examined different definitions of QOL and the domains of these definitions. The most common domains of QOL identified through the analysis of QOL definitions are the physiological, psychological, spiritual and socio-economic domains. 
Phase 2 was undertaken by means of a workshop with expert nurses working with PLWHA in Swaziland who are on ART. The domains that were considered important in the assessment of QOL of PLWHA who are on ART in Swaziland by the participants are the physiological, psychological, spiritual, socio-economic, cognitive and environmental domains. The researcher recommends that the validated domains of QOL should be utilised in the assessment of QOL of PLWHA who are on ART in Swaziland.

\section{Acknowledgements}

The study was funded by a Unisa bursary. The author also acknowledges support from the Swaziland Ministry of Health, RFMH VCT centre staff and the nurses who participated in the study.

\section{Competing interests}

The authors declare that they have no financial or personal relationship(s) which may have inappropriately influenced them in writing this paper.

\section{Authors' contributions}

TTN was the doctoral candidate that conducted the research. TRM (University of South Africa) and BLD (University of South Africa) jointly supervised the conduct of the project

\section{References}

Abuja Declaration on HIV/AIDS, tuberculosis and other related infectious diseases, 2001 viewed 08 July 2009, from http://www.un.org/ga/aids/pdf/Abuja-declaration.pdf

Addington-Hall, J.A. \& Kalra, L., 2001, 'Who should measure quality of life?', BMJ 322, 1417-1420. http://dx.doi.org/10.1136/bmj.322.7299.1417, PMid: 11397754 PMCid: 1120479

Andrews, M.M. \& Boyle, J.S., 2003, Transcultural concepts in nursing care, Lippincott Williams and Wilkins, Philadelphia.

Babbie, E.R. \& Mouton, J., 2003, The practice of social research, 3rd edn., Oxford University Press, Cape Town.

Baldacchino, D. \& Draper, P., 2001, 'Spiritual coping strategies: a review of the nursing research literature', Journal of Advanced Nursing 34(6), 833-841. http://dx.doi. org/10.1046/j.1365-2648.2001.01814.x, PMid: 11422554

Berlim, M.T. \& Fleck, M.P.A., 2003, “"Quality of life”: A brand new concept for research and practice in psychiatry', Brazilian Association of Psychiatry 25(4), 2-6.

Burns, N. \& Grove, S.K., 2005, The Practice of Nursing Research: Conduct, Critique, and Utilization, 5th edn., Elsevier Saunders, St. Louis.

Carr, A.J., Gibson, B. \& Robinson, P.G., 2001, 'Is quality of life determined by expectations or experience?', BMJ 322,1240-1243. http://dx.doi.org/10.1136/ bmj.322.7296.1240, PMid: 11358783 PMCid: 1120338

Code of Professional Nursing Conduct for Swaziland, 1978, Mbabane

Creswell, J.W., 2002, Educational Research: Planning, Conducting, and Evaluating Quantitative and Qualitative Research, Merrill-Pearson Education, Upper Saddle River, New Jersey,

Dalmida, S.S., 2007, Interrelations between spirituality, mental health and immune status among women with HIV/AIDS, Paper presentation at 18th International Nursin Research Congress, focusing on evidence-based practice, 11-14 July. Viewed 23 February 2009, from http://www//stti.confex.com/SHI/congrs07technogram/paper
Delgado, C., 2007, 'Sense of coherence, spirituality, stress and quality of life in chronic illness', Journal of Nursing Scholarship 39(3), 229-234. http://dx.doi.org/10.1136/ bmj.322.7296.1240, PMid: 11358783 PMCid: 1120338

De Vos, A.S., Strydom, H., Fouche, C.B. \& Delport, C.S.L., 2005, Research at grass roots: for the social sciences and human service professions, 3rd edn., Van Schaik, Pretoria.

Dickson, C., 2006, The politics of a national HIV/AIDS response: a synthesis of literature, HLSP Institute.

Emlet, C.A., 2007, 'Experience of stigma in older adults living with HIV/AIDS: a mixed method analysis', AIDS Patient Care and STDs 21(10), 740-752. http://dx.doi. org/10.1089/apc.2007.0010, PMid: 17949273

George, J.B., 2002, Nursing theories: the basis for professional nursing practice, 5th edn., Prentice Hall, New Jersey.

Gillespie, S. \& Kadiyala, S., 2005, HIV/AIDS and food and nutrition security: from evidence to action, International Food Policy Research Institute, Washington DC.

Henderson, W.A., Fall-Dickson, J.M., Schlenk, E.A., Kim, K.H., Matthews, J.T. \& Erlen, J.A., 2008, 'Effects of liver disease on the well-being of persons living with HIV', Journal of the Association of Nurses in AIDS Care 19(5), 368-374. http://dx.doi. Journal of the Association of Nurses in AIDS Care 19(5), 368-374.
org/10.1016/j.jana.2008.05.004, PMid: 18762144 PMCid: 2577288

Holstad, M., Dilorio, C. \& Magowe, M., 2006, 'Motivating HIV-positive women to adhere to antiretroviral therapy and risk reduction behaviour: The KHARMA project', Journal of Issues in Nursing 11(1), viewed 25 July 2008, from http://www. project, , Journal of Issues in Nursing 11(1), viewed 25 July 2008, from http://WWW. tableofcontents/volume112006/NO1Jan31/tpc29-416063.aspx

Holzemer, W.L., Human, S., Arudo, J., Rosa, M.E., Hamilton, M.J, Corless, I. et al., 2009, 'Exploring HIV stigma and quality of life for persons living with HIV infection', Journal of Nurses in AIDS Care 20(3),161-168. http://dx.doi.org/10.1016/j. jana.2009.02.002, PMid: 19427593

Hughes, A, Davis B \& Gudmundsdottir, RN. 2008. Can you give me respect? Experiences of the urban poor in a dedicated AIDS nursing home unit. Journal of the Association of Nurses in AIDS Care 19(5):342-356.

Kasiram, M., Dano, B. \& Partab, R., 2006, 'Intimacy and HIV/AIDS', SA Fam Pract 48(2), 54-55.

Keith, K.D., 2001, 'International quality of life: current conceptual measurement and implementation issues', International Review of Research in Mental Retardation 24, 49-74. http://dx.doi.org/10.1016/S0074-7750(01)80005-7

Kirk, M., 2002, 'The impact of globalization and environmental change on health: challenges for nurse education', Nurse Education Today 22, 60-71. http://dx.doi. org/10.1054/nedt.2001.0720, PMid: 11886231

McMeans, A.R., 2001, Nutrition and HIV/AIDS, HIV nursing curriculum, Baylor College of Medicine, Houston, Texas.

Ministry of Health and Social Welfare, 2007, National health policy, Government of the Kingdom of Swaziland, Mbabane.

Ministry of Health and Social Welfare, 2006-2008, National multi-sectoral strategic framework for HIV and AIDS, Government of the Kingdom of Swaziland, Mbabane.

Ministry of Health and Social Welfare, 2009-2014, National multi-sectoral strategic framework for HIV and AIDS, Government of the Kingdom of Swaziland, Mbabane.

Nyika, A., 2007, African reliance on traditional medicine for the treatment of HIV/AIDS, viewed 11 July 2008, from http://www.medicalnewstoday.com/articles/65460.php

Polit, D.F. \& Beck, C.T., 2008, Nursing research: generating and assessing evidence for nursing practice, 8th edn, Lippincott Williams and Wilkins, Philadelphia.

Potter, P.A. \& Perry, A.G., 2005, Fundamentals of nursing, 6th edn., Mosby, St Louis, Missouri.

Scarinci, E.G., Griffin, M.T.Q., Grogoriu, A. \& Fitzpatrick, J.J., 2009, 'Spiritual wellbeing and spiritual practices in HIV-infected women: a preliminary study', Journal of the Association of Nurses in AIDS Care 20(1), 69-76. http://dx.doi.org/10.1016/j. the Association of Nurses in AIDS Care
jana.2008.08.003, PMid: 19118773

Stanhope, M. \& Lancaster, J., 2004, Community and public health nursing, 6th edn., Mosby, St Louis, Missouri.

Swaziland Millennium Developmental Goals, viewed 03 August 2008, from http:// www.indexmundi.com/swaziland/millenium-development

Uys, L., Chirwa, M., Kohi, T., Greeff, M., Naidoo, J. \& Makoae, L., 2009, 'Evaluation of a health setting-based stigma intervention in five African countries', AIDS Patient Care and STDs 23(12), 1059-1066. http://dx.doi.org/10.1089/apc.2009.0085, PMid: 20025515, PMCid: 2832642

World Health Organization Quality of Life Group. 1995. The World Health Organization Quality of Life Assessment (WHOQOL): a position paper from the World Health Organization. Social Science and Medicine 41(10):1403-1409. 